\title{
SALVAGE CYSTECTOMY FOLLOWING FAILED \\ DEFINITIVE RADIATION THERAPY FOR \\ TRANSITIONAL CELL CARCINOMA OF BLADDER
}

\author{
JOHN W. KONNAK, M.D. \\ H. BARTON GROSSMAN, M.D. \\ From the University of Michigan Medical Center, \\ Ann Arbor, Michigan
}

\begin{abstract}
Between 1971 and 1983 we performed 18 salvage cystectomies on patients with recurrent transitional cell bladder cancer initially treated with definitive radiation therapy $(5,500$ $6,820 \mathrm{R}$ ). The interval between tumor diagnosis and radiation ranged from zero to twenty-one years (mean 3.5 years), and the interval between radiation therapy and cystectomy ranged between six months and twelve years (mean 2.5 years). Early major complications occurred in 5 patients, and there was one early and one late postoperative death. The overall patient survival from the time of diagnosis to death or the present (1985) ranged from two to thirty-one years (mean 9.8 years), and from the time of radiation to the present or death ranged from one to nineteen years (mean 6.2 years). The overall crude five-year survival from the time of cystectomy excluding 2 patients operated on in 1982 and 1983 was 50 per cent, however 3 of these patients died of cancer after five years. Breakdown of survival of these patients by stage demonstrated the best survival in patients with carcinoma in situ and Stage A or no neoplasm at the time of cystectomy. This report confirms the value of salvage cystectomy after radiation failure in invasive transitional cell bladder cancer.
\end{abstract}

High energy external beam radiation therapy has been widely used as standard or alternative definitive treatment for invasive transitional cell carcinoma of the bladder for over twenty years. The results using this form of therapy have been disappointing, with failure rates as high as 72 per cent and five-year survival rates of 14 to 36 per cent. ${ }^{1.2}$ Previous reports have demonstrated that selected patients who fail definitive radiation therapy may be treated or "salvaged" using subsequent cystectomy with reasonable continued survival. ${ }^{36}$ Herein we report our experience with 18 such patients.

\section{Material and Methods}

Between 1971 and 1983, 18 patients were treated by cystectomy for persistent or recurrent transitional cell carcinoma of the bladder following definitive high energy external beam radiation therapy. All patients had recurrent or persistent tumor proved by transurethral biopsy prior to cystectomy, and clinical staging included cystoscopy and bimanual examination, excretory urography, chest films, and bone scans, in addition to routine history, physical examination, hematologic studies, and blood chemistries. Patients with resectable ncoplasms localized to the pelvis underwent salvage cystectomy. The records of these patients were reviewed for date of initial diagnosis, initial therapy, dates and dosage of radiation therapy, and interval between radiation therapy and salvage cystectomy. Details of the operative procedure including type of cystectomy and urinary diversion, duration of operation, blood loss, operative and postoperative complications 
and deaths, and stage at operation were noted. Crude survival rates from the time of diagnosis, radiation therapy, and salvage cystectomy were determined and grouped by stage.

\section{Results}

The mean age of the 18 patients undergoing salvage cystectomy was sixty-five years, with a range from fifty to eighty-two years. All patients were male. The initial therapy for bladder neoplasm was transurethral resection in 7 patients, partial cystectomy and transurethral resection in 2 patients, partial cystectomy and radiation therapy in 1 patient, and radiation therapy in 8 patients. The interval between tumor diagnosis and definitive radiation therapy ranged from zero to twenty-one years, with a mean of 3.5 years. Failure of initial therapy with development of invasive neoplasm or presentation with invasive neoplasm was the indication for administration of radiation therapy in all cases. The dosage of radiation could be determined in 9 patients, and ranged between 5,500 and $6,820 \mathrm{R}$. In 9 patients the exact dosage could not be determined from the records. All patients had biopsy-proved persistent or recurrent neoplasm prior to cystectomy. 'The interval between treatment with radiation therapy and salvage cystectomy ranged between six months and twelve years, with a mean of 2.5 years. Staging studies prior to cystectomy including bone scans and chest films were negative for metastatic disease. In addition, the bladders were deemed resectable on bimanual examination at the time of cystoscopy. Excretory urography demonstrated bilateral hydronephrosis in 5 cases, unilateral hydronephrosis in 3 cases, and normal upper tracts in 10 cases. Other studies such as computed tomography, liver-spleen scans, and lymphangiography were not routinely performed.

\section{Surgical Procedures}

Salvage cystectomy consisted of a total cystoprostatectomy in all 18 patients. A variety of urinary diversions were employed, including ileal conduit in 10 patients, bilateral cutaneous ureterostomy in 4 patients, cutaneous ureterostomy and transureteroureterostomy in 2 patients, jejunal conduit in 1 patient, and ureterosigmoidostomy in 1 patient. Two of the bilateral cutaneous ureterostomies were performed as palliative urinary diversion prior to the total cystectomy. Mean operative time was 6.3 hours, with a range of 2.25 hours to 9.5 hours. Operative blood loss could be determined in 15 patients, and ranged from 2 to 16 units, with a mean of 6.5 units. Mean postoperative hospital stay was seventeen days, with a range of seven to fifty-eight days.

\section{Complications}

Major and minor early operative complications are listed in Table I. There were eight major and three minor complications in 8 patients. Major complications developed in 5 patients $(28 \%)$. There were three rectal lacerations. All were closed primarily, but in 1 patient a leak developed at the closure site necessitating colostomy; this was eventually closed. Another rectal laceration patient went into renal failure, a ureteral leak developed, and sepsis and death ensued. The third rectal laceration patient had a postoperative myocardial infarction and a small-bowel obstruction developed which resolved spontaneously. In the patient with a ureterosigmoidostomy a leak and a fecal fistula developed. He had a colostomy, conversion of his ureterosigmoidostomy to a colon conduit, a small-bowel fistula developed treated with an ileostomy, and he eventually died of renal failure and sepsis eight months postoperatively. The patient with pelvic abscess underwent drainage and uneventful recovery. Late complications included ureteral stenosis in 2 patients, stomal stenosis in 1 patient, and small-bowel obstruction in 1 patient.

TABle: I. Complications

\begin{tabular}{lc}
\hline \multicolumn{1}{c}{ Complications } & No. Pts. \\
Early complications & \\
Major & 3 \\
Rectal laceration & 1 \\
Myocardial infarction & 1 \\
Leak, ureterosigmoidostomy & 1 \\
Pelvic abscess & 1 \\
Ureteral leak & 1 \\
Small-bowel obstruction & \\
Minor & 1 \\
Wound infection & 1 \\
Prolonged ileus & 1 \\
$\quad$ Atelectasis & \\
Late complications & \\
Ureteral stenosis & 1 \\
Stomal stenosis & 1 \\
Small-bowel obstruction & 1 \\
\hline
\end{tabular}


TABLE II. Histologic grade and pathologic stage at operation

\begin{tabular}{|c|c|c|c|c|c|}
\hline \multirow[b]{2}{*}{ Stage } & \multicolumn{5}{|c|}{ Grade- } \\
\hline & CIS & I & II & III & Total \\
\hline pT0 $=$ None $*$ & & 1 & 1 & & 2 \\
\hline $\mathrm{pTis}=\mathrm{CIS}$ & 3 & & & & 3 \\
\hline $\mathrm{pTl}=\mathrm{A}$ & & & 2 & & 2 \\
\hline $\mathrm{pT} 2=\mathrm{B}-1$ & & & & & 0 \\
\hline pT $3 a=B-2$ & & & 2 & 1 & 3 \\
\hline $\mathrm{pT} 3 \mathrm{~b}=\mathrm{C}$ & & & & 4 & 4 \\
\hline $\mathrm{pT} 4 \mathrm{a}=\mathrm{D}-1$ & & & & 4 & 4 \\
\hline TOTALS & 3 & 1 & 5 & 9 & 18 \\
\hline
\end{tabular}

*Neoplasm rcmoved at diagnostic transurethral resection.

There was one early and one late postoperative death resulting from the aforementioned complications.

\section{Patient Survival}

The pathologic stage and grade of the tumors found at operation are listed in Table II. Patients with Stage D-1 had prostatic involvement by neoplasm. The patients with no neoplasm had transurethral resection of their tumors prior to cystectomy. Five-year survival by stage is shown in Table III. Two patients operated on in 1982 and 1983 are alive and disease-free, but are excluded because of their short follow-up. The overall crude five-year survival from the time of cystectomy was 50 per cent. However, 3 of these patients died of cancer after five years: 2 with Stage A disease and 1 with Stage B-2 cancer. One patient with carcinoma in situ died eight months postoperatively with no neoplasm. The overall patient survival from the time of tumor diagnosis to death or the present (1985) ranged from two to thirty-one years, with a mean of 9.8 years. The survival from time of radiation therapy to death or the present ranged from one to nineteen years, with a mean of 6.2 years.

\section{Comment}

While the results of treatment of bladder cancer with definitive radiation therapy have been disappointing, with recurrence or failure in up to 72 per cent of cases, ${ }^{1.2}$ this form of therapy continues to be employed in selected patients. ${ }^{3}$ In addition, there remains a substantial pool of patients who have already undergone definitive radiation therapy. Early reports of cystectomy after definitive radiation therapy were discouraging because of high operative
TABLE III. Crude five-year survival by stage

\begin{tabular}{|c|c|c|c|}
\hline \multirow[b]{2}{*}{ Stage } & \multirow{2}{*}{$\begin{array}{l}\text { Total } \\
\text { No. }\end{array}$} & \multicolumn{2}{|c|}{$\begin{array}{c}\text { Five-Year } \\
\text { Survival }\end{array}$} \\
\hline & & No. & $\%$ \\
\hline No neoplasm & 1 & 1 & 100 \\
\hline CIS & 3 & 2 & 67 \\
\hline A & 2 & 2 & 100 \\
\hline B-1 & 0 & . & \\
\hline B-2 & 3 & 2 & 67 \\
\hline $\mathrm{C}$ & 4 & 1 & 25 \\
\hline D-1 & 3 & 0 & 0 \\
\hline TOTALSS & 16 & 8 & 50 \\
\hline
\end{tabular}

mortality. ${ }^{7.8}$ Recent reports, however, have demonstrated unexpectedly favorable results in selected patients who failed definitive radiation therapy, with continued crude five-year survival of up to 43 per cent and operative mortality below 10 per cent. ${ }^{3.6}$ The results in the present small series of 18 patients with a crude five-year survival of 50 per cent in 16 patients, and an early operative mortality of 6 per cent in 18 patients are consistent with these findings. Because the size of the total pool of patients treated with definilive radiation therapy from which this select series was drawn is unknown, no comment can be made regarding the efficacy of salvage cystectomy as a planned procedure for failure of definitive radiation treatment. In selected patients who fail definitive radiation therapy, salvage cystectomy appears to be appropriate treatment. Frieha and Fay$\mathrm{sal}^{6}$ report a five-year survival of 43 per cent in 40 patients undergoing salvage cystectomy compared with a five-year survival of only 15 per cent in 124 radiation failure patients not undergoing cystectomy. ${ }^{6}$

Salvage cystectomy was part of a continuum of treatment for bladder neoplasm in this series. The mean interval between diagnosis and irradiation was 3.5 years, but the range was from zero to twenty-one years. The interval from radiation therapy to cystectomy ranged from six months to twelve years, with a mean of 2.5 years. After cystectomy, the five-year survival in 16 patients was 50 per cent. As might be expected, the best results occurred in patients who had no tumor in the cystectomy specimen because of complete removal at the time of diagnostic transurethral resection and in patients with carcinoma in situ or Stage A, while the worst results occurred in patients with invasive tumors. The survival in patients with low- 
stage disease of B-2 or less $(7 / 9,78 \%)$ was significantly better than that in patients with Stages $C$ and D-1 $(1 / 7,14 \%)(p=0.04$, Fisher's exact test, two tailed). Survival from the time of tumor diagnosis to death or the present ranged from two to thirty-one years, with a mean of 9.8 years.

Major operative complications occurred in 5 of 18 patients, for a major complication rate of 28 per cent which is similar to other series. ${ }^{3.6}$ Rectal laceration was the most frequent serious complication. Rectal lacerations closed primarily after definitive radiotherapy are at increased risk for subsequent complications. In only 1 of 3 patients so treated did the individual do well without a subsequent colostomy. Crawford and Skinner ${ }^{4}$ noted fewer complications in patients undergoing a two-stage operative procedure with initial urinary diversion; no complications occurred in 7 male patients in whom the staged cystectomy was done through a combined abdominal-perineal approach. ${ }^{4}$ One patient in our series died eight months after a series of complications associated with ureterosigmoidostomy; this form of urinary diversion seems ill-advised in salvage cystectomy.

Salvage cystectomy is the treatment of choice for recurrent localized bladder cancer after definitive radiation therapy that cannot be adequately treated with less aggressive techniques, i.e., transurethral resection. The results are at least as good as those obtained with primary cystectomy, and just as with nonsalvage cystectomy, survival is related to stage. ${ }^{9}$ Nevertheless, these encouraging results with low-stage tumors should not be interpreted as justifying primary radiotherapy with salvage cystectomy in treatment failures. The limitation inherent in this approach is that some patients who could potentially be cured with primary cystectomy may not be recognized as having recurrent dis- ease until that disease is relatively advanced and associated with a poor prognosis. A randomized study from Britain evaluating this method of therapy has demonstrated a significantly better survival in younger patients receiving primary cystectomy as opposed to primary radiation therapy and subsequent salvage cystectomy. ${ }^{10}$ Despite this caution about the general approach to advanced localized bladder cancer, salvage cystectomy is a well tolerated and effective therapy for patients with low stage recurrences following definitive radiation therapy.

Section of Urology C5 112 Box 03 University of Michigan Medical Center Ann Arbor, Michigan 48109

(DR. KONNAK)

\section{References}

1. Buschke $F$, and Jack $G$ : Twenty-five years experience with supervoltage therapy in the treatment of transitional cell carcinoma of the bladder, AJR 199: 387 (1967).

2. Cummings KB, et al: Observations on definitive Cobalt 60 radiation for cure in bladder carcinoma: 15 year follow-up. J Urol 115: 152 (1976).

3. Blandy JP, et al: T3 bladder cancer-the case for salvage crstectomy: Br J Urol 52: 506 (1980).

4. Crawford ED, and Skinner DG: Salvage cystectomy after irradiation failure, J Urol 123: 32 (1980).

5. Smith JA, and Whitmore WF Jr: Salvage cystectomy for bladder cancer after failure of definitive irradiation, ibid 125: 643 (1981).

6. Freiha FS, and Faysal MH: Salvage cystectomy; Urology 22: 496 (1983)

7. Hecker GN, et al: Radical cystectomy after supervoltage radiotherapy: J Urol 91: 256 (1964).

8. Higgins PM, Hamilton RW, and Hope-Stone HF: The hazards of total cystectomy after supervoltage irradiation of the bladder, Br J Urol 38: 311 (1966)

9. Whitmore WF Jr, et al: Radical cystectomy with or without prior irradiation in the treatment of bladder cancer. J Urol 118: $184(1977)$.

10. Bloom HJG. Hendry WF, Wallace DM, and Skeet RG: Treatment of T3 bladder cancer: controlled trial of pre-operative radiotherapy and radical cystectomy versus radical radiotherapy; Br J Urol 54: 136 (1982). 